\title{
Distal locking of femoral nails: a prospective comparative study of two different fluoroscopy assisted techniques
}

\author{
Saroj Kumar Patra ${ }^{1}$, Bishnu Prasad Patro ${ }^{1}$, Sidharth Samal ${ }^{1}$, \\ Mahesh Chandra Sahu ${ }^{2}$, Biswa Bhusana Mohanty ${ }^{3}$
}

\author{
${ }^{1}$ Department of Orthopaedics, IMS and SUM Hospital, Siksha O Anusandhan University, K8, Kalinga Nagar, \\ Bhubaneswar 751003, Odisha, India \\ ${ }^{2}$ Central Research Laboratory, IMS and SUM Hospital, Siksha O Anusandhan University, K8, Kalinga Nagar, \\ Bhubaneswar 751003, Odisha, India \\ ${ }^{3}$ Department of Anatomy, IMS and SUM Hospital, Siksha O Anusandhan University, K8, Kalinga Nagar, \\ Bhubaneswar 751003, Odisha, India
}

Received: 16 November 2015

Accepted: 16 December 2015

\section{*Correspondence:}

Dr. Saroj Kumar Patra,

E-mail: drsarojk_patra@yahoo.com

Copyright: $($ ) the author(s), publisher and licensee Medip Academy. This is an open-access article distributed under the terms of the Creative Commons Attribution Non-Commercial License, which permits unrestricted non-commercial use, distribution, and reproduction in any medium, provided the original work is properly cited.

\section{ABSTRACT}

Background: The purpose of this study is to compare the radiation exposure and time required for distal femoral locking by two different fluoroscopy dependent free hand techniques.

Methods: Two different free hands fluoroscopic assisted distal locking of femur was adopted. First one, traditional method of locking femur in which free hand drilling of femur done with lateral view of femur. Second one is one where femur was drilled with anterior-posterior view of femur in image intensifier. In each method 150 femurs was operated. All the surgeries are performed by same surgeons. Total time duration for distal locking and radiation exposures in terms of fluoroscopy shots in each procedure was compared.

Results: The time duration of distal locking with this novel method (second) was only 4 mins (average) and number of fluoroscopy shots are 8 (average) which is significantly less than routine freehand technique (first) i.e. $14 \mathrm{~min}$ (average) and 18 (average) fluoroscopy shots.

Conclusions: Our novel method is significantly less time consuming and minimal radiation exposure compared to traditional free hand technique.

Keywords: Femur, Interlocking, Distal locking, Radiation hazards

\section{INTRODUCTION}

Interlocking has revolutionise the management of diaphyseal femur fracture. ${ }^{1,2}$ Fluroscopy is an essential requirement for nailing of femur in both for fracture reduction and distal locking. But over use of it has increases cancer risk among surgeons and hospital staffs. Proximal and distal locking is essential to prevent secondary shortening and malrotation. ${ }^{3}$ Proximal locking has minimal difficulty with the proximal mountedjigs. Distal locking by jig attached to nail usually fails because of insertion induced nail deformation. As already documented distal femur locking need maximum time and radiation exposure as compared to other steps of surgery. ${ }^{11}$

To simplify distal locking lot of procedures has been adopted, still fluoroscopy dependent free hand technique is the gold standard and universally accepted. ${ }^{4-7}$ Fluoroscopy assisted free hand technique is the method in many centres all over world. Radiation exposure to staff and patient is a real concern with this method. ${ }^{8-10}$ 
We developed a simple fluoroscopy assisted technique where we used to put screws in anteroposterior view of femur by targeting distal locking hole impression on nail. The accuracy of this method is checked by guide wire to decrease radiation exposure. Our intention was to popularise this novel method and decrease the duration and radiation exposure while locking distal holes of femoral nail.

\section{METHODS}

Total 300 patients with diaphyseal femur fractures were selected for the study. To decrease the sample error, prospectively every odd patient was selected for the first method and every even patient was selected for the second method. Each group had 150 patients each.

All the surgeries are performed by same surgeons from March 2011to May 2015. No specific nail was selected and nails of different make and different material was used as per cost of operation package. Nails diameter and length was chosen as per the need of patient and was not influenced by study. Time duration and number of fluoroscopy shots was recorded for distal locking. Proximal locking of nail was not included in study as it was mostly performed through proximally mounted jigs.

\section{Surgical procedure}

\section{Screw fixation by traditional free hand technique (First)}

After nail insertion into the intra-medullary canal, image intensifier is rotated to visualise the lateral view of femur. Image intensifier is so adjusted to get the circular image of the distal nail hole. Image intensifier in lateral position, femur is drilled aiming at the circular hole in free hand without any jig. We encounter lot of difficulty in getting true lat view as patient is in fracture table and opposite leg obstructed proper image intensifier positioning. The lateral view positioning depends on the technician. It takes lot of time to get a proper lateral view. Distal locking femur with image intensifier in lateral position leaves little space for the drill adding difficulty with this method. After getting true lateral image two screws are put in sequence with help of sounding by the guide wire inside the nail. Total time consumed and fluoroscopy shots are recorded.

\section{Screw fixation by our novel method (Second)}

After fracture reduction and nail insertion into the medullary canal a lateral view of the femur was taken with image intensifier. Lateral view taken to know the level of nail in relation to femur and guide for the skin stab. It does not require true lateral image or circular hole of the nail in fluoroscopy as we are only interested to know the level of nail in relation to femur and skin. With just one shot image intensifier is changed to anterior posterior (AP) view. In AP view first distal screws is drilled at level determined at lateral view and in line with the screw hole in AP view. Confirmation of drill and screw in place is done by guide wire sounding method. Second screw is given in the same manner and confirmed by guide wire. Interesting facts we observed in our method we hit the target in first attempt in almost all cases. Total time consumed and fluoroscopy shots are recorded.

\section{RESULTS}

The following parameters were observed:

1. Total time taken to complete the distal screws fixation.

2. No of fluoroscopy shots taken to complete the procedure.

All observations are done by a single observer and stop watch to minimized error (Table 1).

The duration of distal locking in traditional (first) free hand technique was 14 mins (Range is from 8 mins to 25 mins). Number of fluoroscopy shots were 18 (Range is 10 to 89 ).

Duration of distal locking in our novel method (Second) was 4 mins (Range from 3 mins to 9 mins). Number of fluoroscopy shots was 8 (Range from 4 to 18 ).

By our novel method there is reduction of 71.4 percent in time consumption and 55.5 percent reduction in fluoroscopy shots.

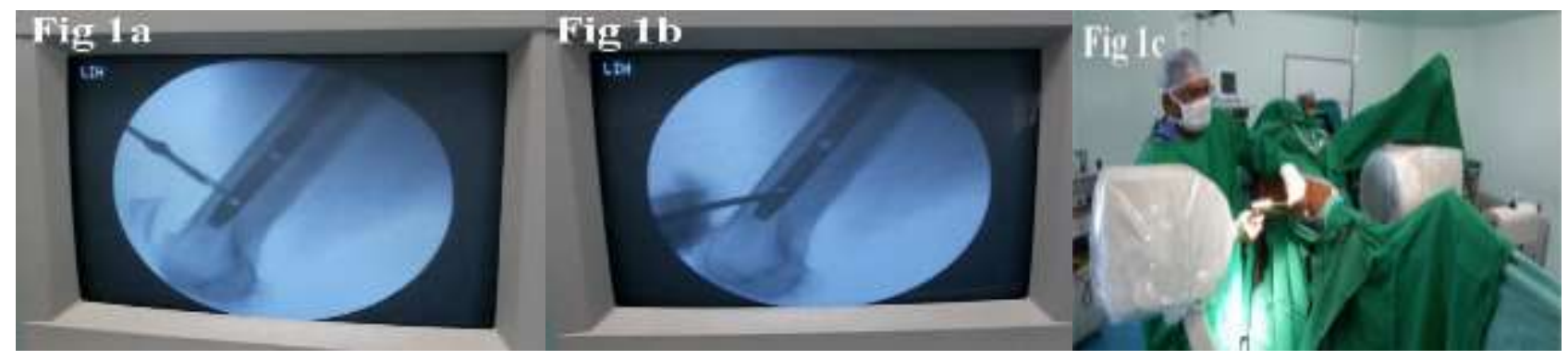

Figure 1a: Skin incision on free hand technique. Figure 1b: Hammering along the line of distal screw hole. Figure 1c: Hammering of steinmann pin for distal screw fixation. 

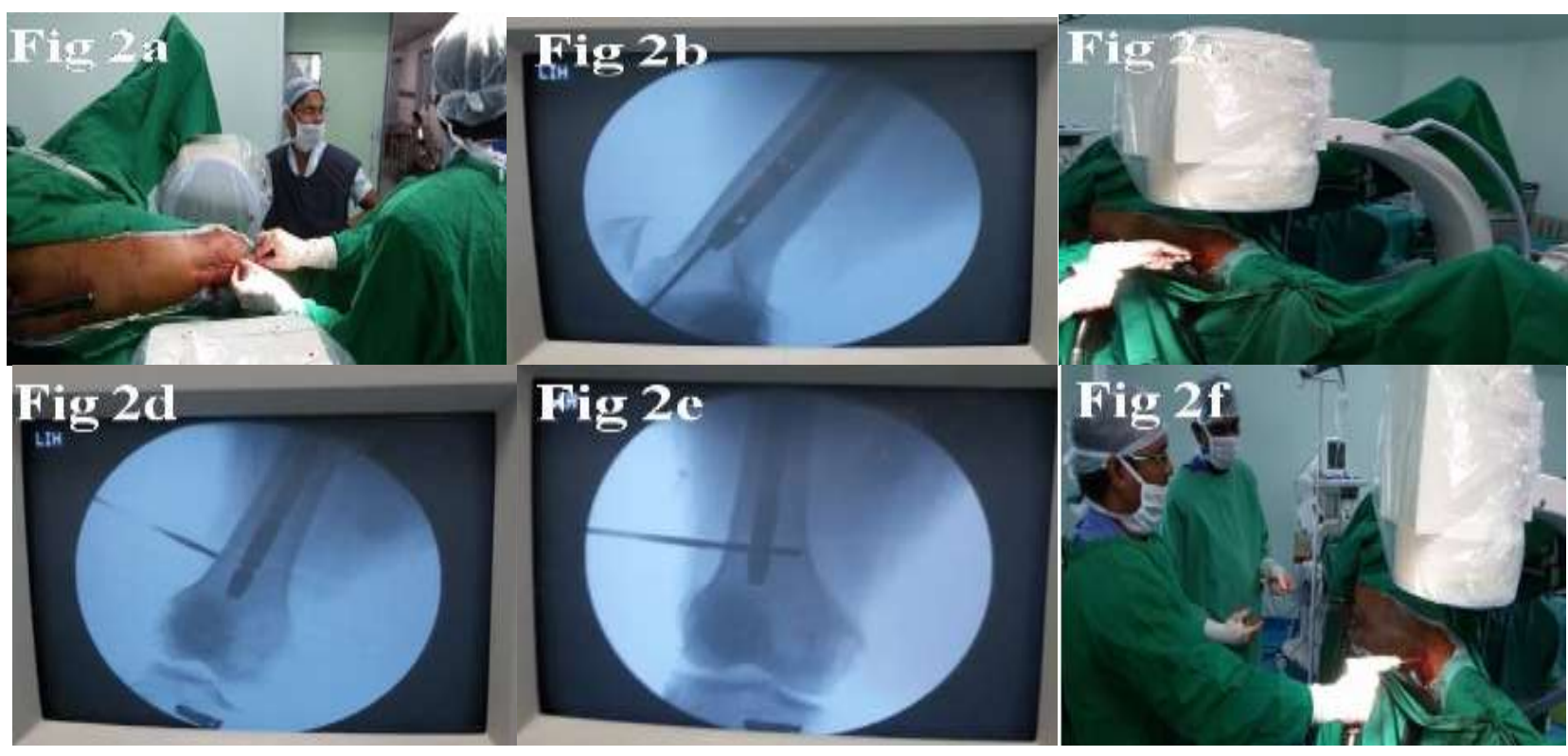

Figure 2a: Line of nail in lateral view. Figure 2b: Confirmation of line of nail in C-arm. Figure 2c: Drilling for distal screw hole in AP view. Figure 2d: Drilling for distal screw hole in C-arm. Figure 2e: Drilling for distal screw.

Figure 2f: Confirmation by guide wire.

Table 1: Two different free hand technique of distal femoral locking.

\begin{tabular}{|lllll|}
\hline Method & $\begin{array}{l}\text { Time } \\
\text { consumption in } \\
\text { minute }\end{array}$ & $\begin{array}{l}\text { Fluoroscopy } \\
\text { shots }\end{array}$ & \\
\hline & Average & Range & Average & Range \\
\hline \multicolumn{1}{|c|}{$\begin{array}{l}\text { Traditional } \\
\text { method } \\
\text { (first) }\end{array}$} & 14 & $8-25$ & 15 & $10-89$ \\
\hline $\begin{array}{l}\text { Our novel } \\
\text { method } \\
\text { (second) }\end{array}$ & 4 & $3-9$ & 6 & $4-18$ \\
\hline
\end{tabular}

\section{DISCUSSION}

Interlocking of femur had revolutionised the management of diaphyseal fractures. ${ }^{1,2}$ Even segmental and comminuted fracture management became simpler with early ambulation and good recovery in almost all patients. ${ }^{12-14}$ During interlocking procedure maximum radiation occurred at distal locking as observed by Sanders et al. ${ }^{11}$ In an attempt to reduce the radiation several fluoroscopy independent proximally mounted jigs were tried but unfortunately most of them are failed because they do not compensate the insertion induced nail deformation. Still fluoroscopy assisted free hand locking technique is the commonest method worldwide. We adopted fluoroscopy assisted free hand technique similar to the traditional method with little modification. Here we first delineated the nail location and hole position with one lateral view followed by locking in AP view. Here there is enough space for the power drill and less chance of contamination. By our novel method there is reduction of 71.4 percent in time consumption and 55.5 percent reduction in fluoroscopy shots. With simple modification the time and radiation both are reduced significantly.

As the case selection was randomised and operated by same surgeons and observed by one assistant the error was minimised.

Our novel method is as simple as routine free hand technique, so it is possible to adopt this procedure in all hospitals where fluoroscopy is available. It does not need any extra training for the surgeon or cost to the Institution. Learning curve is not too stiff and just getting used to the steps is all that is needed.

\section{CONCLUSION}

Our study gave a fair indication and results in terms of radiation exposure and time duration compared to the traditional method of fluoroscopy assisted free hand technique distal femoral locking. We presume this method may save surgical time and decrease radiation exposure. Neither this procedure is difficult nor gadget dependent besides the fluoroscope, this can be preferred method of distal femoral locking. 
Funding: No funding sources

Conflict of interest: None declared

Ethical approval: The study was approved by the institutional ethics committee

\section{REFERENCES}

1. Brumback RJ. The rationales of interlocking nailing of the femur, tibia, andhumerus. ClinOrthopRelat Res. 1996;324:292-320.

2. Kempf I, Leung KS, Grosse A. Practice of Intramedullary Locked Nails: Scientific Basis and Standard Techniques. Heidelberg, Germany: Springer, Verlag. 2002.

3. Kuntscher G. Practice of Intramedullary Nailing. Springfield, IL: Charles C Thomas Publishers. 1967.

4. Kelley SS, Bonar S, Hussamy OD. A simple technique for insertion of distal screws into interlocking nails. J Orthop Trauma. 1995;9:227-30.

5. MacMillan M, Gross RH. A simplified technique of distal femoral screwinsertion for the Grosse-Kempf interlocking nail. ClinOrthopRelat Res. 1988;226:252-9.

6. Hudson I. Locking nailing: an aid to distal targetting. Injury. 1989;20:129-30.
7. Rao JP, Allegra MP, Benevenia J. Distal screw targeting ofinterlocking nails. ClinOrthopRelat Res. 1989;238:245-8.

8. Riley SA. Radiation exposure from fluoroscopy during orthopaedic surgical procedures.ClinOrthopRelat Res. 1989;248:257-60.

9. Sanders R, Koval KJ, DiPasquale T. Exposure of the orthopaedic surgeon to radiation. J Bone Joint Surg Am. 1993;75:326-30.

10. Skjeldal S, Backe S. Interlocking medullary nailsradiation doses indistal targeting. Arch Orthop Trauma Surg. 1987;106:179-81.

11. Sanders R, Koval KJ, Dipasquale T, Schmelling G, Stenzler S, Ross E. Exposure of the orthopaedic surgeon to radiation.

12. Bick EM. The intramedullary nailing of fractures. Clinical Orthopaedics \& Related Research. 1968;60:5-12.

13. Brumback RJ, Toal TR, Murphy-Zane MS, Novak VP, Belkoff SM. Immediate weight-bearing after treatment of a comminuted fracture of the femoral shaft with a statically locked intramedullary nail. Journalof Bone \& Joint Surgery. 1999;81:1538-44.

14. Schatzker J. Fractures of the distal femur revisited. Clinical Orthopaedics \& Related Research. 1998;347:43-56.

Cite this article as: Patra SK, Patro BP, Samal S, Sahu MC, Mohanty BB. Distal locking of femoral nails: a prospective comparative study of two different fluoroscopy assisted techniques. Int Surg J 2016;3:23740. 